\title{
EL PERRO DEL HORTELANO, DE PILAR MIRÓ: UNA ADAPTACIÓN NO TAN FIEL DE LA COMEDIA DE LOPE DE VEGA
}

\section{María José Alonso Veloso}

\author{
Universidad de Vigo
}

Cuando Pilar Miró decide acometer la adaptación de un clásico del teatro español, El perro del hortelano, de Lope de Vega, no hace más que seguir una vieja tradición que se remonta a los mismos comienzos del género cinematográfico. Como apunta Juan de Mata Moncho Aguirre (1999b: 225), «desde sus inicios, el cine español ha requerido de la materia argumental que proporcionan los textos teatrales, aun cuando nada haya más anticinematográfico que la pieza escénica, situada en el polo opuesto a los principios básicos que trajo el cine con su técnica antinaturalista».

Miró se incorpora así a una larga nómina de cineastas en una etapa - tras las versiones realizadas en el período mudo, en el primer período sonoro y en la etapa de postguerra (1940-1975) - caracterizada por un declive del teatro comercial, que hace bajar el número de estrenos y autores nuevos, y por el incremento significativo de las adaptaciones 
de novelas. En la década de los 90 el cine español sigue inspirándose en el teatro y son una mínima muestra de este interés por nuestros clásicos tanto la adaptación de Miró como la realizada por Gerardo Vera a partir de la tragicomedia de Fernando de Rojas La Celestina ${ }^{1}$. El gusto por revisitar obras teatrales clásicas no es exclusivo, no obstante, de la cinematografía española, como se puede deducir a partir de las abundantes adaptaciones suscitadas, por ejemplo, por las obras dramáticas de Shakespeare, uno de los autores más recurrentes en el panorama de las adaptaciones.

Aunque la versión de Miró no demuestra, por tanto, originalidad en la elección de un texto literario como base de una película, sí supone una ruptura tajante respecto a la trayectoria profesional recorrida por la directora desde el estreno, en 1981, de una de las películas de mayor éxito comercial en España: El crimen de Cuenca, realizada en 1979, pero que no pudo ser llevada a la gran pantalla hasta dos años después por presiones de la justicia militar, incómoda debido a que su argumento se basa en uno de los más célebres errores judiciales sucedidos en España y supone una denuncia tajante del empleo de la tortura. El perro del hortelano tampoco guarda relación alguna con otros títulos de la filmografía de su directora: La petición (1976), Gary Cooper que estás en los cielos (1980) o Hablemos esta noche (1982).

La larga lista de títulos teatrales llevados al cine demuestra la naturalidad con la que se acepta el trasvase de uno a otro género, pero lo cierto es que las relaciones entre cine y literatura no han estado exentas de polémica a lo largo de la historia. En el caso de las vinculaciones teatro-cine, se ha discutido mucho sobre la presunta superioridad de uno sobre el otro, sobre el ascenso del cine en detrimento del espectáculo teatral, o sobre las luchas denodadas del séptimo arte por desvincularse mediante los grandes avances técnicos conseguidos en las últimas décadas.

Pese a las diferencias en la producción de sentido que se derivan del hecho de que los significantes se suceden en una dimensión temporal en literatura y en una dimensión espacial y temporal en el caso del cine, lo cierto es que ambas artes coinciden en su capacidad para alber-

1 Para algunos críticos de cine, como José Enrique Monterde (1996: 9), los intentos de adaptación de la literatura del Siglo de Oro no están marcados precisamente por el éxito: «Salvo muy raras excepciones, esos esfuerzos no han pasado de coyunturales operaciones». 
gar los códigos narrativos ${ }^{2}$. Y este punto de encuentro hace posibles tanto las adaptaciones como el análisis de las mismas.

Para el estudio de la adaptación realizada por Pilar Miró que me propongo, considero necesario tener en cuenta advertencias como las pronunciadas por Carmen Peña-Ardid (1999: 13-14) en el sentido de que existen aspectos diferenciadores, significativos y creadores de la adaptación que no suponen, necesariamente, una traición al original escrito: «La mayoría de los estudios sobre las adaptaciones (especialmente de la novela al cine) fundamentan casi todo su análisis en un cotejo con la obra literaria - mucho más atento a las semejanzas y equivalencias que a las transformaciones de sentido- como si la razón de ser de la recreación fílmica fuera parecerse lo más posible, "valer por" el texto originario». Asimismo, la estudiosa considera necesario entender la adaptación como un proceso en el que convergen modelos, códigos y tradiciones que «distan mucho de limitarse a la fuente literaria» (Peña-Ardid 1999a: 14) ${ }^{3}$. Y las necesarias transformaciones -que no traiciones-que se producen en el paso del texto escrito al relato filmado explican que autores como Jorge Urrutia (1999: 36) planteen el siguiente reto: «mejor que de adaptación, hablemos de metamorfosis».

Por otra parte, un estudio comparativo como el que me propongo ha de partir del hecho de que el cine consiguió hace tiempo romper con los principios básicos del teatro a los que había estado sujeto inicialmente. Esta desvinculación determina la no coincidencia exacta de las adaptaciones con el original, debido a la existencia de numerosos elementos diferenciadores de cine y literatura, entre los que conviene mencionar los que siguen ${ }^{4}$ : en el teatro, el espectador se sitúa a una distancia determinada e invariable, se produce una visión totalizadora del espacio de la acción y no existen cambios de perspectiva, si se exceptúan los cambios de escena; en cuanto al cine, registra una distancia variable entre el espectador y la escena dentro de la misma, la escena se divide

2 Peña-Ardid (1999b: 129) resume este hecho asegurando que «si los códigos narrativos pueden manifestarse tanto en la literatura como en el cine, ello se debe a que las imágenes cinéticas y la cadena de signos discretos de la lengua comparten algunos rasgos sensibles comunes: la temporalidad y la secuencialidad».

3 Peña-Ardid (1999a: 14) apoya la idea de adoptar nuevos criterios para el estudio de las adaptaciones cinematográficas «que no se limiten a explicar el film en función exclusiva del texto literario (...) y que sean capaces de reconocer su autonomía y sus diferencias por el hecho de que pertenece a un lenguaje distinto pero también porque se inserta en un sistema y un contexto que no son los de la obra originaria».

4 Teniendo en cuenta la teoría de Béla Balázs, Peña-Ardid (1999b) sistematiza estos puntos de desencuentro, este proceso de individualización vivido por cine y teatro. 
en planos separados, se da un encuadre variable - ángulo y perspectiva- de las imágenes detalladas dentro de la escena y hace uso del montaje, principio organizador y ordenador de las tomas separadas.

Aun siendo consciente, pues, de que el análisis de una adaptación no puede restringir sus propósitos a la mera comparación entre el texto literario y el guión ${ }^{5}$ y menos desde una perspectiva de superioridad del primero respecto al segundo, y de que hay que prestar especial atención también a los recursos propiamente cinematográficos, sí considero positivo abordar ese cotejo, como un primer paso en el estudio, en el caso de una película considerada en los medios de comunicación como «absolutamente fiel» a la comedia de Lope de Vega tras su estreno.

\section{CAMBIOS QUE DELATAN}

La comparación entre los diálogos de los personajes de la película de Miró y de la obra teatral de Lope permite hablar de la existencia de tres tipos de modificaciones del texto literario: las supresiones, que son las más abundantes; las sustituciones de palabras o frases; y las adiciones. En todos los casos, y como norma general, los cambios parecen debidos a dos propósitos fundamentales: una modernización léxica y un aligeramiento de la materia en beneficio de la acción. Ambos objetivos confluyen en otro más general de acercamiento al público.

Por lo que respecta a la eliminación de partes de la obra de Lope de Vega, la mayoría de los casos suponen elipsis muy breves, aunque la extensión de numerosos pasajes elididos aconseja su mención así como una explicación detenida de los mismos ${ }^{6}$. Así, por ejemplo, la película de Miró elimina una parte de la discusión de Diana y los criados por la irrupción de un intruso en palacio (vv. 25-60), así como las disculpas de Fabio por no atraparlo y los intentos de la condesa de bus-

5 Considero acertadas las palabras de Pere Gimferrer (1999: 56) cuando afirma que «los problemas de adaptación pueden ser fundamentalmente de dos órdenes; problemas de equivalencia de lenguaje y problemas de equivalencia del resultado estético obtenido mediante el lenguaje».

6 En mi análisis incluiré entre paréntesis, siempre que lo considere pertinente, la numeración de los versos suprimidos en la obra de Lope, de acuerdo con la edición de Mauro Armiño (El perro del hortelano, Madrid, Cátedra, 1998). 
car la verdad entre las mujeres de su casa (vv. 106-202). El afán de resumir se observa también en el recorte sufrido por las reflexiones de Teodoro, confuso al intuir el amor de Diana (vv. 847-888); la digresión en la que apuntan los pensamientos de Teodoro sobre la condesa (vv. 1308-1327); la conversación entre Tristán y Marcela, tras la ruptura de ésta con Teodoro (vv. 1486-1507); diversos momentos del monólogo de Teodoro cuando Diana elige a su futuro marido; la conversación entre Tristán y Teodoro, en la que éste lamenta la decisión de su ama, y el monólogo de Marcela por la pérdida de su amante (vv. 17401807); el monólogo de Teodoro sobre el amor y respuesta de Tristán, tras el episodio de los bofetones (vv. 2246-2262); Federico y Ricardo conciertan la muerte de Teodoro y se inserta la fábula de las dos ollas (vv. 2372-2404); Tristán cuenta a Teodoro el proyecto de acabar con su vida (vv. 2527-2543); el monólogo de Teodoro en el que cuenta su propósito de huir (vv. 2562-2575); el monólogo de Diana, que muestra su dolor por perder a Teodoro y se culpa a sí misma por cometer el error de fijarse en un inferior (vv. 2716-2729); el diálogo entre Tristán y Furio tras el embuste que situará a Teodoro en el mismo escalafón social que Diana y narración de aquél a Federico y Ricardo, que piden cuentas a Tristán por no haber matado a Teodoro (vv. 2900-2985); la conversación entre Teodoro y Marcela, en la que ésta demuestra conocer el amor del primero por Diana y se considera vengada (vv. 29963015); y Tristán cuenta a Teodoro el engaño sobre su supuesto padre (vv. 3238-3254).

La eliminación de versos, muy importante desde un punto de vista cuantitativo, supone en términos generales privar al espectador de partes no fundamentales para la trama de la obra y para el seguimiento de su acción, especialmente cuando afectan a personajes no principales. De hecho, se observa que la película corta episodios una vez que ha aportado datos suficientes sobre los mismos y no se producen, por tanto, lagunas significativas. Pero la supresión se hace habitual — de forma llamativa, aunque quizá lógica desde una perspectiva cinematográficacuando se trata de monólogos de personajes: Miró opta por recortar bastante las reflexiones de Teodoro y Diana, en línea con un fenómeno descrito por estudiosos como Peña-Ardid (1999: 23): «El paso del texto literario al film supone indudablemente una transfiguración no sólo de los contenidos semánticos (...) el adaptador además de transformar debe reducir y condensar el material de partida a veces drásticamente».

Pero todo proceso de selección y reducción repercute siempre sobre el mensaje y, en el caso de El perro del hortelano, provoca un adelga- 
zamiento de la profundidad psicológica de los personajes y un mayor esquematismo en la delimitación de los mismos y sus caracteres. Se prima, pues, la acción sobre la reflexión, y a los amantes, sumergidos en un océano de dudas y contradicciones, no les está permitido divagar tanto acerca de sus sentimientos. Asistimos al comportamiento de los personajes, pero, en ocasiones, al espectador se le ocultan los pensamientos e impresiones que lo determinan.

Menos importantes, desde un punto de vista cuantitativo y cualitativo, son las sustituciones a que son sometidos los versos de Lope. Por un lado, los cambios de palabras o frases persiguen una modernización deliberada de la expresión literaria - hay que tener en cuenta que se trata de un texto del siglo XVII y su adaptación se concibe para un espectador de finales del siglo $\mathrm{XX}-\mathrm{y}$, por el otro, hay modificaciones inmotivadas y que parecen obedecer a razones que sólo el adaptador conoce.

El análisis del proceso modernizador a que es sometido el texto teatral permite afirmar que existe una falta de coherencia en las decisiones adoptadas a la hora de sustituir unas palabras o expresiones por otras diferentes y más actuales. Además de variaciones derivadas de la evolución fonética experimentada por el español, se observa una tendencia clara a sustituir los pronombres enclíticos por formas antepuestas al verbo: «te dije» por «díjete» (v. 343), «me ha pedido» por «hame dicho» (v. 515), « ¿te burlas?» por «búrlaste» (v. 772), «de no quererte casar» por «de no te querer casar» (v. 97), «ahora» por «agora» (v. 972), «porque» por «que» (v. 973), «ansí» por «así» (v. 1082), «nos pagaréis» por «pagar tenéis» (v. 2416), «ofrecerla» por «ofrecella» (v. 1146), etc. Lo curioso es que este criterio renovador no se aplica de forma uniforme y los cambios conviven con el mantenimiento de formas arcaicas: «fuese» (v. 841), «escuchalle» (v. 1987), «si no servillo, celebrallo» (v. 2083), «bañole» (v. 2245), «aqueste alboroto» (v. 3128), «yo a matalle» (v. 3230).

Aunque existen casos en los que la sustitución implica la búsqueda de términos más o menos sinónimos para evitar un léxico incomprensible hoy en día - es lo que sucede en «anda falido estos días», cambiado por «anda muy pobre estos días» (v. 605), o también en «ponerse un jaco», sustituido por "vestirse una armadura» (v. 1157), y en «frisones de su coche», que se convierte en «caballos de su coche» (2476) - , lo cierto es que la mayor parte de las veces parece deberse a una mera cuestión de estilo o gusto del guionista: «muestra aquí tu comedimiento» sustituye a «muestra aquí tu entendimiento» (v. 238); 
«escribe y búscame», a «aquí aguardo; vuelve luego» (v. 600); «guarda, guarda sus secretos», a «iqué traigo de pensamientos!» (v. 686); «buenos van mis pensamientos», a «poned esas sillas luego» (v. 688); y «ies que tienes duda que en nuestro favor acuda», a «ipues pones duda que a su ilustre sangre acuda?» (vv. 942-943). Pero el cambio puede afectar a expresiones más largas, como ocurre cuando se cambia «mira que fue bueno el aviso, Marcela, de los tapices que miras», por «pues yo diré que ser prudente, Marcela, conviene, si bien lo miras» (vv. 1512-1514).

Es cierto que las sustituciones mencionadas en este segundo apartado no tienen gran influencia sobre el texto, el mensaje o el desarrollo de la acción, pero parecen inmotivados e innecesarios en una película que se autodenomina adaptación fiel de la obra teatral de Lope.

Finalmente, por lo que respecta al tratamiento del texto literario, cabe decir que existen adiciones - muy pocas-, casi siempre provocadas por la supresión de un fragmento extenso. Por ejemplo, el afán de resumir lo ocurrido en cien versos omitidos (vv. 107-202) explica que el guión de la película añada, para que sea comprensible el desarrollo de la acción, varios versos en los que la condesa de Belflor llega a la conclusión de que el intruso de palacio no la busca a ella, sino a una de sus criadas.

Pero la adición más significativa, por sus implicaciones posteriores, es la que afecta no a diálogos entre los personajes teatrales, sino a la propia acción y a su traducción en imágenes: frente al comienzo del texto literario, in media res, con Teodoro y Tristán huyendo tras ser descubiertos en casa de Diana, la película opta por explicar la razón de esa huida con la introducción de una imagen, en primer plano, de Marcela y Teodoro besándose. Este cambio no sólo implica una apropiación del punto de vista por parte de la cámara, que desea subrayar ese componente amoroso de la acción y adquiere un marcado carácter subjetivo, sino también una reorganización de los diálogos, que cambian de lugar. De hecho, el espectador no escucha las palabras de los fugitivos en su huida apresurada, en las que muestran su temor de haber sido reconocidos, hasta el verso 105 .

Frente a los cambios explicados anteriormente, considero que la inserción de ese primer plano, un recurso típicamente cinematográfico, condiciona de forma global la interpretación que el espectador hace de la obra. Se diría que Pilar Miró opta por destacar el componente amoroso de la trama, la vertiente de los sentimientos, por encima del 
conflicto suscitado por la honra, quizá con criterios comerciales. Esta elección, que en lenguaje cinematográfico se subraya con la filmación de un tipo de plano muy significativo y nada objetivo, se refuerza además con otros dos primeros planos que chocan abiertamente con el concepto de decoro en el Siglo de Oro: el primero (v. 3065) muestra un beso apasionado de Diana y Teodoro cuando éste se decide a viajar a España para evitar problemas, antes de que se sepa que el secretario de la condesa procede de familia noble y es, por tanto, su igual; el segundo (v. 3158), cuando Tristán ya ha hecho correr la mentira mencionada y Diana cree en la nobleza de Teodoro, tras la conversación con su supuesto padre, Ludovico.

Gimferrer (1999: 65) advierte que «no siempre la mejor adaptación es la más fiel», porque «una adaptación genuina debe consistir en que, por los medios que le son propios - la imagen - el cine llegue a producir en el espectador un efecto análogo al que mediante el material verbal - la palabra - produce la novela en el lector. No reproducir o mimetizar los recursos literarios, sino alcanzar, mediante recursos fílmicos, un resultado análogo (...) al obtenido precisamente en el libro por aquéllos» ${ }^{7}$. Desde esta perspectiva, la reescritura de la obra lopesca por parte de Miró parece no cumplir esos requisitos atribuidos a la mejor adaptación posible de un texto literario. Sin entrar a valorar su calidad como producto cinematográfico, parece haberse producido un sutil cambio en el sentido y también en el efecto provocado en el espectador. Quizá, una traición camuflada al mensaje latente en la comedia barroca.

Otra adición, importante por situarse al término de la obra teatral pero inexplicable desde el punto de vista del desarrollo de la trama, implica la prolongación del diálogo entre Ludovico, Teodoro, Diana y Tristán tras ese final cuajado de bodas: el criado del secretario recién ascendido en la escala social se queja ante éste por haberlo casado y Diana promete al padre fingido que cuidará a Teodoro. El añadido aporta información intrascedente e irrelevante para el desenlace o el desarrollo de la trama.

Más afortunado parece, desde la perspectiva del propósito modernizador que se esconde en la mayoría de las modificaciones, el cambio realizado en el párrafo final del texto lopesco — habitual en el Siglo de

7 La cursiva es mía. Este autor prioriza así, por encima del seguimiento más o menos exhaustivo del texto literario, el respeto a la intención, al mensaje global que subyace al mismo. 
Oro y exigido por la representación, pero inapropiado en la actualidad-, en el que el personaje se dirige al «senado noble» y da por concluida «la famosa comedia» de El perro del hortelano. Pilar Miró resuelve el anacronismo adjudicando esas palabras de Teodoro a los coros, que las cantan de fondo, por lo que resultan casi inapreciables para el espectador.

\section{UNA CONFIGURACIÓN DISCURSIVA OBJETIVA}

Dejando ya la comparación entre el texto literario y los diálogos cinematográficos, conviene adentrarse en los recursos típicamente fílmicos utilizados por Pilar Miró para llevar a la pantalla una obra de nuestro teatro clásico, habida cuenta de que la elección de unos u otros puede desvelar los propósitos del adaptador.

De acuerdo con la teoría de Casetti ${ }^{8}$ acerca de las cuatro configuraciones discursivas del punto de vista que aparecen eventualmente inscritas en el discurso narrativo fílmico, en la adaptación de Pilar Miró se observa un predominio de la objetiva. Ésta se caracteriza por planos que permiten una aprehensión inmediata de los hechos, de lo esencial de la acción, sin que se ponga en evidencia ni al enunciador (o narrador) ni al enunciatario (o espectador). Impera, pues, la neutralidad y no parece representarse el punto de vista de nadie. De hecho, y quizá debido a un propósito de mayor acercamiento a la obra de Lope, se puede hablar de una filmación muy «teatral»: es cierto que la cámara se mueve, pero lo hace en muchos casos de forma poco evidente y muy funcional, limitándose a seguir los pasos de algún personaje o a registrar su movimiento de entrada o salida. Esta afirmación no implica, no obstante, que no se usen recursos típicamente cinematográficos; lo que ocurre es que éstos no están remitiendo constantemente a la subjetividad del narrador, recordando a cada paso su mediación.

Como muestra de lo dicho, se puede mencionar la existencia de diálogos que confirman el hecho de estar ante una película con muy poco montaje ${ }^{9}$ : se resuelven en un solo plano y la cámara realiza un travelling

8 Sigo el resumen de la teoría de este autor realizado por Gaudreault y Jost (1995).

9 A propósito del papel que corresponde al montaje dentro de las distintas técnicas cinematográficas, se puede recordar la propuesta de Lev Kuleshov, resumida por 
muy lento para seguir a los personajes, por ejemplo durante un paseo. Asi, cuando Diana hace leer a Teodoro el papel con el que intenta hacerle ver su amor y las causas del mismo (vv. 551- 565).

El propósito de objetividad que se hace patente con el predominio de la configuración discursiva objetiva —en línea con el dejar hacer, con ese asistir inmediato a la acción de los personajes del espectáculo teatral- se subraya con la abundancia de planos-secuencia en la película de Miró. Este hecho deja traslucir una técnica cinematográfica poco supeditada a los efectos de montaje: son muchas las secuencias - unidades básicas de acción en el cine- configuradas por un único plano, sin cortes, lo que supone una aproximación más, un guiño de la directora, a la teatralidad.

Justo al principio de la película, tras el primer plano del beso, se recurre a un plano-secuencia para mostrar el diálogo entre Diana y Fabio sobre el intruso. Aunque a continuación se recurre a la técnica del plano / contraplano, en un nuevo plano-secuencia la cámara sigue a los personajes por las estancias en esa especie de locura colectiva que se apodera del palacio. También el primer diálogo entre Teodoro y Diana se resuelve con un plano-secuencia, en el que la cámara sigue a los personajes, que caminan dentro del plano.

Esta aparente neutralidad en el tratamiento de la materia cinematográfica se rompe, con cierta frecuencia, en otros diálogos, especialmente los de contenido amoroso y aquellos en los que están involucrados personajes principales, quizá debido a la subjetividad que tiñe lo narrado. La directora recurre a planos alternos del marqués y la condesa cuando aquél se declara; el diálogo posterior entre Teodoro y Diana, cuando el secretario entrega el escrito encargado por la condesa, está estructurado en una serie de plano / contraplano; y la misma técnica sirve a continuación para mostrar la conversación entre Teodoro y Marcela, en la que ésta narra el compromiso adquirido por la condesa para casarles. La preferencia de Miró por este mecanismo cinematográfico —que concede un papel relevante a las labores de montaje- en diálogos amorosos o en enfrentamientos dialécticos entre los amantes se demuestra con la existencia de nuevos ejemplos de secuencias configuradas en plano / contraplano: Teodoro y Diana se

Sánchez-Biosca (1996:101) así: «El material del cine (...) es la realidad, pero ésta está sometida a una estilización, es decir, a su conversión en signo. Y el instrumento de dicha estilización es el principio de montaje, el cual, en la misma operación, discursiviza». 
desplazan en una góndola y, de forma no muy sutil, la mujer intenta quitarle de la cabeza a Marcela, justo antes del final del primer acto de la obra teatral (vv. 1023-1172); nueva conversación de Diana con su secretario, en la que éste le declara su amor y ella disimula ante el desconcierto de Teodoro, antes de propinarle unos bofetones (vv. 21452218), a los que asistimos por medio de un plano lateral conjunto; Teodoro cuenta a Diana que su pretendida nobleza es un engaño mediante primeros planos sucesivos de ambos (vv. 3266-3316).

Desde la perspectiva de la enunciación cinematográfica, y pese al predominio de la objetividad ya mencionado, existen numerosos casos en los que la subjetividad de la imagen resulta más que aparente. De acuerdo con la teoría de Gaudreault y Jost (1995: 50-51), los primeros planos a los que he hecho referencia, pero también esos otros que ofrecen imágenes de besos con las que se destaca el contenido amoroso de la película, poseen un claro carácter subjetivo al implicar siempre el subrayado de un objetivo concreto - unos determinados personajes-. Pero son indicios de subjetividad también esos casos raros en los que se produce un descenso del punto de vista por debajo del nivel de los ojos: las secuencias de picado / contrapicado, aunque no exageradas, adquieren un claro valor metafórico. Miró opta por estos encuadres cuando desea subrayar las diferencias sociales, pero también el dominio ejercido por Diana sobre todos los que la rodean. En este sentido, hay que mencionar la conversación entre la condesa y Teodoro (v. 510), en la que se aprovecha que los personajes están en unas escaleras para destacar la sumisión del secretario mediante una serie de picado / contrapicado. No es casualidad que otro pequeño picado / contrapicado domine el diálogo entre Diana y el marqués (v. 740), porque se consigue así crear en el espectador la sensación de que la mujer dirige en todo momento la situación. Hay un caso, no obstante, en el que la cámara no se coloca en un contrapicado, sino creando un plano lateral que consigue el mismo efecto: situar socialmente a los mencionados personajes, una arriba y otro abajo, cuando la condesa hace valer su superioridad para impedir el casamiento de su secretario con Marcela (v. 2210).

Existen momentos en los que el relato cinematográfico parece depender de la mirada de algún personaje, pero la resolución final de las secuencias impide hablar de auténticos ejemplos de cámara subjetiva. Creemos estar viendo cómo se acercan Teodoro y Tristán a través de los ojos de Diana (v. 325), mientras una voz en off expresa sus pensamientos acerca de las cualidades de su secretario y el inconveniente 
de la desigualdad social existente entre ambos, pero, cuando ellos miran, el siguiente plano está tomado por encima del hombro de ella, por lo que es necesario apuntar la existencia de un punto de vista externo. En otro momento, Diana se asoma a una ventana (v. 2134) y observa a Fabio y Teodoro, abajo; por convención, los espectadores creemos ver con su mirada, pero la sucesión de tres planos (largo, corto y largo) nos permite apreciar más de lo que ella podría alcanzar desde su situación. Lo mismo sucede cuando Marcela y Teodoro se reconcilian - gracias a la mediación de Tristán-, y Diana, acompañada por Anarda, observa lo que sucede tras una celosía: tampoco se puede hablar de cámara subjetiva, porque no se produce en la imagen la distorsión, el impedimento que implica la existencia de la celosía.

En toda la película únicamente se puede afirmar que Miró recurre a la cámara subjetiva, delatada por lo que Gaudreault y Jost califican como «una cierta deformación en relación con lo que juzgamos una visión normal» —exageración del flou, etc.—, cuando la acción se desarrolla en la iglesia: en un determinado momento, y en medio de un monólogo de Teodoro marcado con la técnica de la voz en off, vemos a Marcela a través de sus ojos; de hecho, hay momentos en los que la gente que la rodea estorba la visión de su imagen completa y la subjetividad se subraya con una sucesión de fundidos que van alternando la visión de uno y otro personaje y que contribuyen a crear una atmósfera de subjetividad y de ensoñación relacionados con el enamoramiento.

En términos generales, y pese a las excepciones apuntadas, la adaptación de El perro del hortelano se caracteriza por un predominio de los movimientos funcionales de la cámara y por un escaso trabajo de montaje ${ }^{10}$. Éste se reduce de manera significativa a momentos en los que los diálogos quieren subrayar la tensión amorosa y, quizá, su poca relevancia está determinada por la inexistencia de saltos temporales, hecho que favorece la sucesión ininterrumpida de hechos y personajes.

10 Conviene recordar en este punto las palabras de Sánchez-Biosca (1996: 128) en su análisis del montaje cinematográfico, a medio camino entre un trabajo mecánico y una labor artística, por su relación con los juegos con el punto de vista: «en el despedazamiento de la escana se juega la diferenciación y variedad de los puntos de vista, la pluralidad de miradas, imposibles para el ojo inmóvil del sujeto que asiste a la proyección, tanto como para el espectador teatral. Y es que, al fragmentar, el cine conquista una forma de construir un espacio, un tiempo y una acción en cuanto elementos significantes, es decir, dotados de una considerable dosis de arbitrariedad que los separa de sus referentes y los hace aptos para construir un discurso». Al no «abusar» del montaje, Miró se aproximaría más al espectáculo teatral para el que fue creada la obra de Lope de Vega. 


\section{MONÓLOGOS Y APARTES}

La deuda de la película con el género teatral se comprueba también en el mantenimiento de los habituales «apartes», claves para la creación de cierto grado de complicidad entre los personajes y el espectador: frente a una técnica tan cinematográfica como la inserción de una voz en off que reproduce los pensamientos de los personajes, lo más frecuente es que se opte por dejar que éstos «digan» palabras a las que sólo el espectador tiene acceso y que están vedadas al resto de los seres incluidos en el encuadre. Y la técnica, de origen teatral, recurre en la adaptación de Miró a procedimientos más propios del cine como la mirada o unos gestos; éstos permiten saber que una expresión dada no forma parte de un diálogo con otra persona; es más, no está dirigida a nadie del relato fílmico, sino a alguien extradiegético.

Esta técnica vinculada al espectáculo teatral es recurrente en la película objeto de análisis. Tristán hace un aparte marcadamente teatral y lo subraya como tal dirigiendo su mirada al cielo, cuando Diana da a entender que conoce sus andanzas nocturnas con Teodoro: « $i$ Oxte, puto! ¡Vive Dios, que se sabe todo el cuento!» (vv. 663-664). Otro aparte del mismo personaje, que apoya su condición de «gracioso» de la comedia y hace más pronunciado su papel de enlace con el espectador, se produce cuando los pretendientes nobles de Diana intentan contratar los servicios de Tristán para matar a Teodoro, sin sospechar que trabaja a su servicio; cuando los reconoce, sus palabras dejan de dirigirse a sus interlocutores, un primer plano permite comprobar que mira hacia un lugar indefinido y el sonido subraya tanto el aparte como la intensidad dran atica del momento: ${ }_{i}$ Vive el cielo, que son los pretendientes de mi ama» (vv. 2451-2452).

Pero también personajes principales como Diana y Teodoro recurren al aparte para dar información al espectador sobre sus pensamientos y evitar que el otro se entere de ellos: antes de que la condesa haga escribir al secretario lo que constituye una abierta declaración de amor y un reproche por la supuesta indecisión de Teodoro, murmuran: «iQue aqueste amase a Marcela, y que no tenga prendas para que también me quiera! ¡Que se burlasen de mí! Ella murmura y se queja; bien digo yo que en palacio, para que a callar aprenda, retratos tienen oídos y paredes tienen lenguas» (vv. 2003-2011).

Aunque afirmo que Miró no desprecia elementos de origen teatral como el aparte, éste, en lugar de dirigirse al público que asiste al espec- 
táculo buscando su complicidad, supone a veces que el personaje dirija su mirada a la cámara. De la misma índole son otros gestos estudiados para hacer pensar y descifrar un mensaje sin palabras a algún personaje $o$ al propio espectador: Diana hace a Teodoro un gesto con una mano y la cabeza, interpretable como «¿entiendes?», y con el que evidencia de nuevo su amor (v. 2025); Teodoro repite idéntico gesto, con el mismo significado, ante Marcela cuando decide volver a dejarle (v. 2057).

Los pensamientos de los personajes ${ }^{11}$ se reproducen de dos formas: dejando que el personaje hable — la posibilidad más habitual-, aunque la ausencia de interlocutores hace evidente el carácter de monólogo del parlamento, o utilizando la técnica cinematográfica de la voz en off. La película de Pilar Miró privilegia el primer procedimiento, utilizado en las siguientes secuencias:

- Monólogo de Teodoro (v. 841) que muestra sus sentimientos contradictorios al intentar interpretar las palabras de Diana «no importa que se pierda si se puede perder más». Las palabras del secretario en el texto teatral resultan reducidas drásticamente en la película, de 47 a sólo 6 versos.

- Teodoro murmura ante Marcela su arrepentimiento por haber creído que la condesa se había fijado en él (vv. 944-950).

- Teodoro se muestra desolado tras conocer la decisión de Diana de casarse con el marqués. En la primera parte del monólogo, recortado en la versión cinematográfica, lo vemos hablando, pero la parte final del mismo recurre a la voz en off (v. 1687).

- Monólogo de Teodoro, confundido por los vaivenes en el amor de Diana (vv. 2040-2044).

- Monólogo, en forma de soneto, de Diana: ella interpela al amor y a los celos y se aprecia el enfrentamiento entre el amor y el honor (vv. 2120-2134).

11 Insistiendo en la necesidad de situar las relaciones entre las novelas y sus adaptaciones fílmicas no en el terreno de las equivalencias de lenguaje, sino del resultado estético obtenido, Gimferrer (1999: 63) hace ver la dificultad de llevar a la pantalla algunos recursos típicamente literarios como el monólogo: «Cada lenguaje es lo que es y ni aun en el más óptimo de los supuestos el lenguaje visual podrá obtener equivalencias plenas de recursos que son propios únicamente del lenguaje literario, como es el caso del monólogo interior empleado por Faulkner y Joyce o la técnica del punto de vista desarrollada por Henry James». 
- Dos monólogos de Diana, desesperada por la marcha de Teodoro a España. En el primero, maldice al honor por ser origen de sus problemas (vv. 2622-2628); en el segundo, maldice su origen noble (vv. 2649-2651). El relato cinematográfico suprime la parte más extensa de los pensamientos de la condesa, aquélla en la que recrimina a sus ojos por haberse fijado en un hombre que no es su igual.

Pero hay tres momentos en los que el pensamiento de los personajes es reproducido por una voz en off:

- Monólogo, en forma de soneto, de Diana acerca de las cualidades de su secretario (vv. 325-338).

- Monólogo bastante extenso - aunque reducido a la mitad respecto al texto literario- de Teodoro, quien constata la barrera de la desigualdad social para su amor (vv. 1278-1307).

- Parte del monólogo de Teodoro mencionado arriba en el que un cambio de plano, coincidente con la parte de texto suprimida, permite la transición entre el habla directa del personaje y la voz en off (vv. 1687-1723).

Aunque Pilar Miró parece preferir la técnica de la voz en off para los monólogos más extensos y la voz directa del personaje en cuestión para las reflexiones más breves, no existe en apariencia un criterio definido para la elección de uno u otro. De hecho, dos monólogos de Diana de la misma extensión y con forma de soneto se presentan con técnicas diferentes.

\section{RUPTURA DE LAS UNIDADES CLÁSICAS}

La típica estructuración del teatro clásico en tres actos no se respeta en la adaptación de Pilar Miró: es cierto que los cambios de acto de la obra literaria coinciden en la película con cambios de secuencia, de espacio e incluso de tiempo, pero la filmación presenta constantes 
cortes que no se corresponden con el texto de Lope, utilizando así un típico recurso cinematográfico con el que se consigue evitar la monotonía que se derivaría de la «inmovilidad» de la escena teatral.

Por lo que respecta a la unidad de tiempo - hay que recordar las recomendaciones de la preceptiva acerca de la conveniencia de desarrollar toda la acción en el transcurso de una única jornada-, resulta deliberadamente rota en la película. Frente a la indeterminación temporal en la que tiene lugar la comedia lopesca, la adaptación de Pilar Miró subraya el paso del tiempo y de los días con recursos muy cinematográficos, entre los que cabe mencionar, en primer lugar, la luz de las imágenes exteriores (por ejemplo, las del palacio en el que vive la condesa de Belflor) y, por otra parte, el vestuario de los personajes, especialmente el de Diana. Los espectadores intuyen que ha pasado un día cuando la condesa cambia su vestido.

Así, después del revuelo provocado por las visitas nocturnas de Teodoro a Marcela, el cambio de jornada se subraya no sólo con la luz, sino también con una ambientación en exteriores y la música (v. 325); en la comedia, por el contrario, la acción transcurre sin ningún corte y las acotaciones sólo marcan que Diana está sola con sus pensamientos.

Un corte más violento de escena, por implicar también un espacio nuevo, se registra cuando, después de encerrar a Marcela, Diana surge en la película paseando en barca con Teodoro (v. 1023). El cambio de escena se resalta con un cambio de tiempo - es otro día-, de lugar - un entorno natural y una barca- $-y$, nuevamente, con la música interpretada por un grupo en una fiesta cortesana.

El paso del primer al segundo acto implica la llegada de otro día, un espacio diferente - la iglesia - y la música (v. 1187). A este cambio sucede otro tampoco marcado por Lope: tras un monólogo confuso de Teodoro, Tristán le entrega un papel de Marcela, pero lo hace en un espacio diferente, ya que las imágenes de la película han transportado al espactador desde la salida de la iglesia hasta el interior de la cocina palaciega (v. 1328).

La música destaca otro cambio de secuencia: estamos nuevamente en el exterior y vemos el baile de unos niños desde una ventana (v. 1430), pero accedemos con rapidez al interior del palacio siguiendo los pasos de una criada. Y la transición de un espacio interior a otro exterior, con la habitual irrupción de música —en este caso en off-, permite al espectador asistir a una conversación entre Teodoro y Tristán, cuyos gestos vemos aunque no entendemos sus palabras; sus 
figuras en la barandilla dejan paso a una escena de la condesa y el secretario en una fuente (v. 1656).

Tras numerosos cambios de secuencia en los que alternan espacios exteriores e interiores, la noche y el día, el fin del segundo acto implica no sólo un cambio de lugar —es de noche y la acción se sitúa en el interior de una taberna-, sino, como es habitual en la película de Miró, la inserción de música y unos bailes, si bien de carácter más popular que los anteriores.

La tendencia mencionada de señalar de forma especial los cambios de acto marcados por Lope de Vega se mantiene al final de la película: se oye música, llega el supuesto padre de Teodoro, se celebran las bodas y todos bailan al ritmo de una canción cuya letra forma parte del texto teatral.

En definitiva, frente a la «pobreza» de espacios y ambientación marcada por los recursos técnicos de la época y el propio género de la comedia, muy poco pródigo en indicaciones de las acotaciones teatrales, Miró aprovecha técnicas típicamente cinematográficas - la música, la voz en off, la decoración de espacios, el vestuario, los cortes y el montaje, los cambios de espacio y tiempo- para ofrecer una interpretación personal de la obra clásica ${ }^{12}$ sin por ello apartarse de su texto, aunque provocando un enfoque y una interpretación del espectador diferentes.

\section{REINTERPRETACIÓN Y VIGENCIA DE UN CLÁSICO}

En conclusión, la adaptación estudiada supone una apuesta decidida de Pilar Miró para demostrar, por una parte, la posibilidad de llevar a la pantalla teatro en verso y compaginar éste con un cierto carácter «comercial» de la película; $y$, por la otra, la pervivencia de nuestros

12 Aunque esta cuestión me alejaría del objeto de mi análisis, conviene apuntar que Miró es muy poco realista en la recreación de la época histórica en la que transcurre la acción. Contrastan el lujo, la riqueza y hasta la limpieza de interiores y exteriores, así como el aspecto físico de los personajes _especialmente, los criados-, con las auténticas condiciones de vida del siglo XVII: la suciedad, el mal estado de conservación de las viviendas en las ciudades, la pobreza de las zonas rurales, las deficientes condiciones higiénico-sanitarias... se pueden comprobar, por ejemplo, en Defourneaux (1998). 
clásicos - por ello reciben esa denominación- casi cuatro siglos después de ser escritos ${ }^{13}$. El esfuerzo realizado y la difusión de la obra que conlleva compensan, quizá, esos cambios arbitrarios y en algún caso inmotivados que he mencionado, así como las mutilaciones del texto realizadas en beneficio de la acción. Pese a las dudas de algunos autores sobre la pertinencia de recuperar a determinados clásicos ${ }^{14}$, pese a la lejanía obvia que hoy sentimos respecto a los conflictos de honor del siglo XVII -y de ahí, seguramente, el interés de Miró por profundizar en el contenido amoroso de la historia-, pese al menor carácter comercial de esta película y a sus dificultades para llegar a un público de masas, no cabe duda de que el resultado tiene sentido y de que la adaptación de la comedia lopesca resulta pertinente. Porque, como afirma Gimferrer (1999: 129) ${ }^{15}$ «(..) en el caso de Lope (...), el sentido de la obra no debe buscarse, pues, en sus temas externos, sino en aquello que, sobre tal cañamazo, ha constituido el verdadero foco del interés del autor: la escritura para Lope».

La adaptación de Pilar Miró es, pues, un tributo a la vigencia de nuestros clásicos; también, a veces, un guiño a recursos típicamente teatrales, rememorados de forma manifiesta en muchas secuencias. Pero su versión, afortunada en algunos aspectos y menos apropiada en otros ya señalados, recurre a técnicas cinematográficas que propician en algún momento el enriquecimiento del texto literario y del espectáculo teatral, y que, en todo caso, aportan una perspectiva personal

13 Reflexiona Peña-Ardid (1999: 80-81) sobre la pervivencia de los clásicos a través del cine afirmando que «no nos sorprende el hecho de que, para demostrar la actualidad del arte escénico de Tirso de Molina y del teatro del XVII en general, parezca oportuno resaltar su adecuación para ser traducido al cine, ya que, en definitiva, éste era el requisito que se exigió habitualmente a la literatura cuando se la etiquetaba como cinematográfica».

14 No estoy de acuerdo con las afirmaciones de Monterde (1996: 9) tras el estreno de $E l$ perro del hortelano, en el sentido de considerar oportuna la recuperación de obras de Shakespeare, pero no la de las comedias de Lope de Vega: «Las adaptaciones de Shakespeare (...) no interesan sólo por su valor histórico-cultural, sino por la indiscutible vigencia de sus textos. ¿Podemos decir lo mismo de las comedias de Lope de Vega? ¿Tiene algún interés hoy día el esfuerzo de adaptar al cine una obra como $E l$ perro...? (...) La levedad de buena parte de las cerca de 1.800 piezas escritas por Lope queda muy lejos no sólo de la permanente actualidad de Shakespeare, sino incluso de algunas otras obras de nuestro propio siglo XVII».

15 Este autor propone diferenciar entre la película o la obra teatral como producto de consumo - para un público popular - y como producto estético. Este último aspecto, en el caso de permanecer con el paso del tiempo, confirma la solidez artística de una obra. Y por ello recuerda el caso de obras literarias -entre ellas, todas las obras teatrales de Lope de Vega - que «en el pasado gozaron de amplia popularidad y hoy dejan indiferente al gran público pero apasionan a los estudiosos de la literatura" (Gimferrer, 1999: 128). 
y diferente de la directora. Contra los intentos de asegurar la superioridad del texto literario frente a su versión cinematográfica, de destacar las posibles carencias de ésta, de cuestionar la idoneidad de recuperar piezas teatrales de Lope de Vega, conviene recordar que los recursos técnicos propios del cine «obligan» a un resultado diferente, a una reinterpretación del original cuyo valor no ha de ser menor, sino, simplemente, diferente desde una perspectiva estética.

\section{Referencias bibliográficas}

Defourneaux, Marceline (1998). Daily Life in Spain in the Golden Age. California: Stanford University Press.

GaUdReAult, A. y Jost, F. (1995). El relato cinematográfico. Barcelona: Paidós.

GIMFERRER, P. (1999). Cine y literatura. Barcelona: Seix Barral.

LARRAZ, E. (1986). Le cinéma espagnol des origines à nos jours. París: Les Éditions du Cerf.

LOPE DE VEGA: El perro del hortelano. Madrid: Cátedra, 1998.

MATA Moncho AGUIRRE, J. (1999). «Las adaptaciones teatrales en el cine español», Encuentros sobre literatura y cine. Zaragoza: Instituto de Estudios Turolenses, 225-252.

MONTERDE, J. E. (1996). «El perro del hortelano. Una adaptación inadecuada». Dirigido, 252.

PEÑA-ARDID, C. (coord.) (1999a). Encuentros sobre literatura y cine. Zaragoza: Instituto de Estudios Turolenses.

PeÑA-ARdid, C. (1999b). Literatura y cine. Madrid: Cátedra.

SÁNCHEZ-BIOSCA, V. (1996): El montaje cinematográfico. Barcelona: Paidós. URRUTIA, J. (1999). «Leer, conocer, filmar, decir», Encuentros sobre literatura y cine. Zaragoza: Instituto de Estudios Turolenses, 21-36. 